Some subspecific taxa also exhibit unique chemical profiles. .For example, the two recognised varieties of $N$. candida, var. candida and var. copelandii, produce completely different flavonoids. In $N$. californica, two forms exist with either whitish or yellow farina. This is due to different exudate composition. Again, this reflects a remarkable difference in the biochemical capacity of both forms. It is suggested that they should be recognised as separate varieties. In $N$. standleyi, differences in geographic range, edaphic requirements, aspect, height and indument colour indicate that three distinct subgroups of this taxon exist. This is confirmed by statistical evaluation of their flavonoid patterns. These forms are regarded as chemical races (chemotypes).

\title{
The gametophyte in relation to colonising habit in Himalayan ferns: relevance to reproductive biology
}

\author{
S. C. Verma \\ Department of Botany, Panjab University, Chandigarh-160014, India
}

The Himalayas abound in a variety of ferns occupying diverse habitats from moist ravines and dripping rocks to sunny, open roadsides and forest margins extending from the foothills to nearly $3,500 \mathrm{~m}$ altitude. Fern sporophytes would be at the mercy of their gametophytes to the extent that they express any portion of the genome they convey. Furthermore, the regular sexual cycle might be expected to be restricted to the domain of specific habitats where sporophytic and gametophytic tolerances overlap. The homosporous ferns are unique in possessing potentially hermaphroditic gametophytes which allow the recurrence of intragametophytic selfing, generating thereby completely homozygous sporophytes. Studies on a large number of Himalayan ferns have revealed that the gametophyte generation offers a variety of adaptations, including particularly sequential emergence of gametangia and their duration, position of gametangia, populational characteristics of gametophytes derived from spores of a single sporophyte, and gametophyte-gametophyte interactions that either disproportionately favour or ensure intergametophytic mating.

The colonising and non-colonising species of ferns differ in their gametophyte characteristics. The data on the colonising species of Himalayan ferns are presented with particular reference to Lloyd's concept of predominance of intragametophytic selfing in colonising species of Hawaiian ferns (Holbrook-Walker and Lloyd 1973). There is seemingly a complex correlation between colonising habit, habitat, and ploidy level. The length of the gametophyte generation per se does not help in predicting the predominant mating system of a fern species. It is found that species with notably low gametophyte generation times, like Polystichum species, may possess gametophyte characteristics favouring intergametophytic mating. It is observed that populations of gametophytes contain a variable number of pure archegoniate prothalli, and the proportion of such prothalli amongst the total archegonia-bearing ones, constitutes a sensitive index to infer and compare the relative probabilities of intergametophytic mating between species, and between populations, genotypes and ecotypes within species. 
Holbrook-Walker, S. and Lloyd R. M., 1973. Reproductive biology and gametophyte morphology of the Hawaiian fern genus Sadleria (Blechnaceae) relative to habitat diversity and propensity for colonization. Bot. J. Linn. Soc. 67, 157-174.

\title{
Ferns of the Indo-Nepal border
}

\section{R. B. Srivastava}

\author{
Motihari, India
}

The ferns of the Valmikinagar area of virgin forest have been studied morphologically and cytologically. The area lies on the Nepal frontier at latitude $27^{\circ} 31^{\prime}$, and has a monsoon type of climate. Twenty-five species belonging to 15 genera are recorded and further studies are in progress. Cytological results thus far are summarised in Table 1 .

Table 1. Chromosome numbers of ferns of the Indo-Nepal border

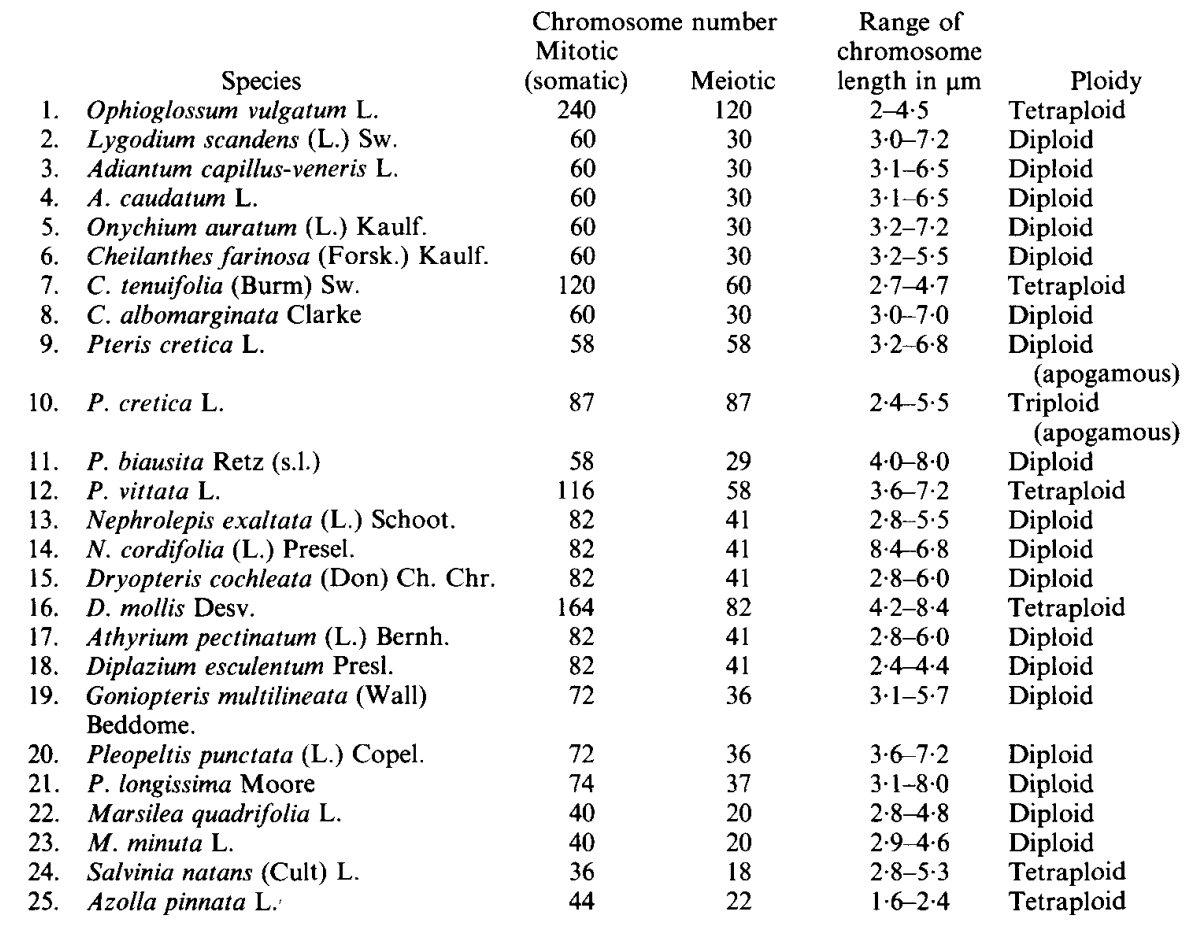

